\title{
CHINESE MEDICINE (CM) matters
}

\section{Chun Un, Lorita Cheang, Jerry Lei, Siu-wai Leung and Hin Wing Yeung*}

\begin{abstract}
Address: International Society for Chinese Medicine (ISCM), A \& C, 1st Floor, Block 2, University of Macau, Av. Padre Tomas Pereira, Taipa, Macao,
\end{abstract} PR China

Email: Chun Un - chun@cmjournal.org; Lorita Cheang - lorita@cmjournal.org; Jerry Lei - jerrylei@cmjournal.org; Siuwai Leung - siuwai.leung@cmjournal.org; Hin Wing Yeung* - hwyeung@cmjournal.org

* Corresponding author

Published: 28 November 2008

Chinese Medicine 2008, 3:16 doi:10.1186/1749-8546-3-16

This article is available from: http://www.cmjournal.org/content/3/1/16

(C) 2008 Un et al; licensee BioMed Central Ltd.

This is an Open Access article distributed under the terms of the Creative Commons Attribution License (http://creativecommons.org/licenses/by/2.0), which permits unrestricted use, distribution, and reproduction in any medium, provided the original work is properly cited.
Received: 28 November 2008
Accepted: 28 November 2008
Happy birthday CM! On 23 November 2006, we launched Chinese Medicine (CM), a peer-reviewed, open access, international, interdisciplinary and scholarly journal in Chinese medicine [1]. Two years on, with the best efforts and sometimes personal sacrifices made by the authors, editorial and advisory board members, reviewers, and the editorial teams in Macao and at BioMed Central in London, we have published a total of thirty-two high quality research and review articles. In addition, four print issues have also been distributed to many individuals and institutions worldwide.

Two years ago, we committed ourselves to publishing valuable research in Chinese medicine. We appreciate all rigorous research methodologies and evidence, whether they are traditional or modern, conventional or alternative, macroscopic or microscopic. All articles (except editorials) published in CM must be peer-reviewed to ensure that they are evidence-based, scientifically justified and ethical. A total of thirteen review articles and eighteen research articles and one editorial have been published. They are important contributions to Chinese medicine, covering a wide range of topics/interests such as acupuncture, materia medica, Chinese medicine formulae, dentistry, allergy, metabonomics, genomics, cardiovascular diseases, liver diseases, cancer, arthritis, ageing, quality control and drug safety, and more. They have been highly accessed and widely cited. As they are indexed and permanently archived by major international scientific repositories and web-based search engines for e-journals such as PubMed, PubMed Central, Potsdam, INIST, e-Depot, CAS, CABI, Citebase, OAIster, Cinahl, Scopus, Scirus, Google Scholar and Zetoc, the general public as well as Chinese medicine researchers can always access them for information and reference.

Not surprisingly, CM published articles on ginseng - a hot research topic. Yue et al. [2] relate the pharmacogenomics of ginseng to 'Yin and Yang' actions, particularly the antitumor, angiomodulating and steroid-like activities of ginsenosides. Mechanistic and functional genomic studies revealed that a group of genes were regulated by ginsenosides in endothelial cells and ginsenosides (Rb1 and Rg1) with opposing activities. Moreover, the authors demonstrate that ginsenosides can act as functional ligands to activate different steroid hormone receptors. Such research findings may help discover the mystery of the diverse pharmacological activities and therapeutic effects of ginseng. The 'Ying and Yang' actions of ginseng, particularly ginsenosides ( Re and Rg3), as reported by $\mathrm{Ng}$ et al. [3], alter cellular redox state of a tumour cell model in opposite directions. Equally fascinating accounts are given by Ko et al. [4] relating the ancient ideas of Yin and Yang in Chinese medicine to the biological concepts of ATP generation, antioxidant and immunomodulation. Wu et al. [5] also introduce us to the modulating effects of American ginseng on pancreatic beta cell activities.

As a natural and holistic approach, traditional Chinese herbal medicine often uses formulae consisting of multiple herbs. The complexity of Chinese medicine formulae is a big technical challenge to the research and quality assurance/control of herbal products. CM has published six articles to address this issue including the compoundoriented and pattern-oriented approaches [6], DNA methods for identification of Chinese medicinal materials [7], 
chemical markers for the quality control of herbal medicines [8], the applications of high-performance liquid chromatograph (HPLC) method in the quality assurance of complex Chinese medicine formulae Dachenggi Tang [9], Gegen Tang granule [10] and herbal products of Radix Aconiti Lateralis Perarata [11]. CM has also published several studies on the complexity of multiple herb formulae, e.g. a systematic approach to revealing the complexity of Chinese herbal medicine formulae [12], an animal study of Yinchenhao Tang on cirrhosis/fibrosis [13] and a clinical study on Duhuo Jisheng Tang for treating osteoarthritis [14].

Clinical studies in Chinese medicine are often not well reported. We have been trying to improve the situation by enforcing the international standards of clinical trial reporting in our published articles. Capodice et al. [15] and Itoh et al. [16] report the applications of acupuncture to treat lower urinary tract symptoms related to chronic prostatitis/chronic pelvic pain and knee osteoarthritis respectively. Another clinical study on treating knee osteoarthritis with Chinese herbal medicine is reported by Lai et al. [14]. A meta-analysis by Liu et al. [17] assesses the effectiveness and safety of Chinese red yeast rice preparations on lipid modification in primary hyperlipidemia. A systematic review by Liu et al. [18] investigates the beneficial effects of green tea on caner prevention by evaluating forty-three epidemiological studies, four randomized trials and one meta-analysis.

In a review article, Wang et al. [19] survey the literature for a list of Chinese herbal ingredients with reported liver protection activities, in which a total of 274 different species and hundreds of active ingredients were examined. In another review article, Adams et al. [20] discuss the pharmacology, medicinal chemistry and clinical studies published for danshen and tanshinone preparations. Itokawa et al. [21] survey the literature between 1976 and mid2008 on the anti-inflammatory, anti-oxidant, anti-HIV, chemopreventive and anti-prostate cancer effects of curcuminoids.

On the front of the so-called 'omics', Qiu et al. [22] demonstrate that metabolic profiling is useful in studying therapeutic mechanisms of herbal medicines such as Herba Cistanches. The Faculty of Dentistry of the University of Hong Kong has contributed two articles to CM on bone formation authored by Wong et al. [23,24]. We hope that this series of papers will bear the fruit of a newly proposed research discipline, dubbed as Evidence-based Integrative Dentistry (EBID). CM encourages submissions in this emerging field.

Two years ago, we committed ourselves to the internationalization and modernization of Chinese medicine [1].
Today, we boast a much internationalized authorship in the Chinese medicine field. The authorship of the published articles covers thirteen countries and regions. We are also proud of the support from the leading scholars and experts in Chinese medicine and integrative medicine serving as our advisory/editorial board members and/or our reviewers.

As of 28 November 2008, the acceptance rate of CM during this two-year period has been $20.13 \%$. In our editorial work, we recognize a great demand for improving English writing skills that are crucial to reporting research findings. We have been providing our authors with extensive English writing assistance and copy-editing, which is why some papers took longer time to publish. We are also planning a scientific writing workshop to help the authors in need.

Two years ago, we committed ourselves to Open Access to 'ensure that the best Chinese medicine research is published and read by the widest possible range of international audience' and that 'in a speedy and professional manner, the scientific value and potential impact of all published articles in CM will be judged and evaluated by the international scientific community' [1]. Today, access and citation data speak for themselves. As of 28 November 2008, the two most viewed articles of all time have recorded access numbers of 14,527 and 10,396 respectively. Eleven out of the thirty-two articles published have been cited and the total number of citations has amounted to 36. The two most cited articles have been cited eight and five times respectively. Recently published articles have also been cited. The access and citation data show that the articles published in CM have high international visibility and accessibility and are tremendously citation friendly as stated in our launch editorial [1]. The data also support that open access articles are immediately read and cited by peers, leading to a quicker and higher number of citations [25-27].

For the future, we strongly encourage our authors to follow the international guidelines for scientific reporting when they submit a manuscript, while rigorous reviews of manuscripts must also be upheld. We firmly believe that the synergy generated by the authors, reviewers and editors will enable this journal to publish more and better papers. We are more convinced now than two years ago that this journal is an exciting medium for fostering open access strengths and evidence-led forces for the advancement of Chinese medicine [1].

\section{Competing interests}

The authors declare that they have no competing interests. 


\section{Authors' contributions}

CU drafted the first version of the manuscript for discussion. Other authors contributed their views and revised the manuscript. HWY led the revision process, integrated all views and finalized the manuscript. All authors read and approved the final manuscript.

\section{References}

I. Yeung HW: Chinese Medicine: a peer-reviewed open access journal for evidence-led Chinese medicine. Chin Med 2006, I: I .

2. Yue PYK, Mak NK, Cheng YK, Leung KW, Ng TB, Fan DTP, Yeung HW, Wong RNS: Pharmacogenomics and the Yin/Yang actions of ginseng: anti-tumor, angiomodulating and steroidlike activities of ginsenosides. Chin Med 2007, 2:6.

3. $\mathrm{Ng} W Y$, Yang MS: Effects of ginsenosides $\mathbf{R e}$ and $\mathbf{R g} 3$ on intracellular redox state and cell proliferation in $\mathbf{C 6}$ glioma cells. Chin Med 2008, 3:8.

4. Ko KM, Leung HY: Enhancement of ATP generation capacity, antioxidant activity and immunomodulatory activities by Chinese Yang and Yin tonifying herbs. Chin Med 2007, 2:3.

5. Wu ZG, Luo JZQ, Luo LG: American ginseng modulates pancreatic beta cell activities. Chin Med 2007, 2: II.

6. Zeng ZD, Chau FT, Chan HY, Cheung CY, Lau TY, Wei SY, Mok $D K W$, Chan CO, Liang YZ: Recent advances in the compoundoriented and pattern-oriented approaches to the quality control of herbal medicines. Chin Med 2008, 3:9.

7. Yip PY, Chau CF, Mak CY, Kwan HS: DNA methods for identification of Chinese medicinal materials. Chin Med 2007, 2:9.

8. Li SL, Han QB, Qiao CF, Song JZ, Cheng CL, Xu HX: Chemical markers for the quality control of herbal medicines: an overview. Chin Med 2008, 3:7.

9. Tang WF, Wan MH, Zhu ZY, Chen GY, Huang X: Simultaneous determination of eight major bioactive compounds in Dachengqi Tang (DT) by high-performance liquid chromatography. Chin Med 2008, 3:5.

10. Song JZ, Han QB, Qiao CF, Yip YK, Xu HX: Simultaneous deter mination of multiple marker constituents in concentrated Gegen Tang granule by high performance liquid chromatography. Chin Med 2007, 2:7.

II. Xie Y, Zhou H, Wong YF, Liu ZQ, Xu HX, Jiang ZH, Liu L: An optimized high-performance liquid chromatography (HPLC) method for benzoylmesaconine determination in Radix Aconiti Lateralis Preparata (Fuzi, aconite roots) and its products. Chin Med 2008, 3:6

12. Gao QT, Li J, Cheung JKH, Ding JDA, Cheung AWH, Zhao KJ, L WZM, Dong TTX, Tsim KWK: Verification of the formulation and efficacy of Danggui Buxue Tang (a decoction of Radix Astragali and Radix Angelicae Sinensis): an exemplifying systematic approach to revealing the complexity of Chinese herbal medicine formulae. Chin Med 2007, 2:12.

13. Liu C, Sun MY, Wang L, Wang GQ, Chen GF, Liu CH, Ping Liu: Effects of Yinchenhao Tang and related decoctions on DMNinduced cirrhosis/fibrosis in rats. Chin Med 2008, 3:I.

14. Lai JN, Chen HJ, Chen CC, Lin JH, Hwang JS, Wang JD: Duhuo Jisheng Tang for treating osteoarthritis of the knee: a prospective clinical observation. Chin Med 2007, 2:4.

15. Capodice JL, Jin ZZ, Bemis DL, Samadi D, Stone BA, Kapan S, Katz $A E$ : A pilot study on acupuncture for lower urinary tract symptoms related to chronic prostatitis/chronic pelvic pain. Chin Med 2007, 2: I.

16. Itoh K, Hirota S, Katsumi $\mathrm{Y}$, Ochi H, Kitakoji $\mathrm{H}$ : A pilot study on using acupuncture and transcutaneous electrical nerve stimulation (TENS) to treat knee osteoarthritis (OA). Chin Med $2008,3: 2$

17. Liu JP, Zhang J, Shi Y, Grimsgaard S, Alraek T, Fønnebø V: Chinese red yeast rice (Monascus purpureus) for primary hyperlipidemia: a meta-analysis of randomized controlled trials. Chin Med 2006, I:4.

18. Liu JP, Xing JM, Fei YT: Green tea (Camellia sinensis) and cancer prevention: a systematic review of randomized trials and epidemiological studies. Chin Med 2008, 3:12.
19. Wang R, Kong J, Wang DL, Lien LLM, Lien EJC: A survey of Chinese herbal ingredients with liver protection activities. Chin Med 2007, 2:5.

20. Adams JD, Wang R, Yang J, Lien EJC: Preclinical and clinica examinations of Salvia miltiorrhiza and its tanshinones in ischemic conditions. Chin Med 2006, I:3.

21. Itokawa H, Shi Q, Akiyama T, Morris-Natschke SL, Lee KH: Recent advances in the investigation of curcuminoids. Chin Med 2008, 3:II.

22. Qiu YP, Chen MJ, Su MM, Xie GX, Li X, Zhou MM, Zhao A, Jiang J, Jia $W$ : Metabolic profiling reveals therapeutic effects of Herba Cistanches in an animal model of hydrocortisone-induced 'kidney-deficiency syndrome'. Chin Med 2008, 3:3.

23. Wong RWK, Rabie B: Chinese red yeast rice (Monascus purpureus-fermented rice) promotes bone formation. Chin Med 2008, 3:4

24. Wong RWK, Rabie B, Bendeus M, Hägg U: The effects of Rhizoma Curculiginis and Rhizoma Drynariae extracts on bones. Chin Med 2007, 2:13.

25. Lawrence S: Free online availability substantially increases a paper's impact. Nature 200I, 4I I:52I.

26. Eysenbach G: Citation advantage of open access articles. PLoS Biology 2006, 4(5):el57.

27. MacCallum CJ, Parthasarathy $\mathrm{H}$ : Open access increases citation rate. PLoS Biology 2006, 4(5):e I76.

Publish with Bio Med Central and every scientist can read your work free of charge

"BioMed Central will be the most significant development for disseminating the results of biomedical research in our lifetime. "

Sir Paul Nurse, Cancer Research UK

Your research papers will be:

- available free of charge to the entire biomedical community

- peer reviewed and published immediately upon acceptance

- cited in PubMed and archived on PubMed Central

- yours - you keep the copyright
BioMedcentral 